\title{
HUMAN PERFORMANCE TOOLS USED AS INCIDENT PREVENTION APPLIED TO A CONSTRUCTION PHASE OF A NUCLEAR POWER PLANT MOCHOVCE
}

\author{
Marek ROLINEC ${ }^{1}$, Karol BALOG ${ }^{1}$ \\ ${ }^{1}$ SLOVAK UNIVERSITY OF TECHNOLOGY IN BRATISLAVA, \\ FACULTY OF MATERIALS SCIENCE AND TECHNOLOGY IN TRNAVA, \\ INSTITUTE OF INTEGRATED SAFETY, \\ ULICA JÁNA BOTTU 2781/25, 91724 TRNAVA, SLOVAK REPUBLIC \\ e-mail: marek.rolinec@stuba.sk, karol.balog@stuba.sk \\ Received: 06.05.2019, Accepted: 10.06.2019, Published: 25.07.2019
}

\begin{abstract}
In order to manage the Construction Safety in a professional and due manner, it is of the key importance to have in place an Occupational Health and Safety Management System, consisting, similarly as a house project, of correct foundations as preparation, planning, procurement, properly set up rules and contractual relations, especially if a site of approx. 5,000 daily manpower is of a concern. Pillars of safe construction follow, i.e. education and training, inspections, communication and, last but not least, human behaviour. The purpose of the following article is to introduce the Human Behaviour Improvement Tools applied in the NPP Mochovce, completion process of Units 3\&4, focusing on the implementation and the observance of the $\mathrm{OH} \& S$ rules.
\end{abstract}

\section{Key words}

Construction safety, human reliability, human behaviour, effective safety communication, communication campaigns

\section{INTRODUCTION}

Construction shall be considered as one of the most important industries in Slovakia, whereas approx. $5 \%$ of the total number of persons is employed in the field of civil engineering. The construction industry is the third sector consisting of the highest number of employed persons. If fatalities and severe damages to health would be subject to assessment, the construction industry could be rated as one of the top three hazardous industries. Table 1 compares the number of accidents in the four most risky industries of the national economy assessed in the period from 2009 to 2014. 
Table 1 Occupational accidents' development as per particular industries (National Labour Inspectorate of the SR) [1]

\begin{tabular}{|c|c|c|c|c|c|c|c|c|c|c|c|c|}
\hline \multirow{2}{*}{ Activity } & \multicolumn{6}{|c|}{ Fatalities } & \multicolumn{6}{|c|}{$\begin{array}{l}\text { Severe Damage to Health }+42 \text { Sick } \\
\text { Leaves } \\
\text { Severe Damage to Health upon } \\
111 / 1975(2009-2010)\end{array}$} \\
\hline & 2009 & 2010 & 2011 & 2012 & 2013 & 2014 & 2009 & 2010 & 2011 & 2012 & 2013 & 2014 \\
\hline Industry & 8 & 11 & 9 & 12 & 12 & 7 & 720 & 750 & 58 & 61 & 43 & 46 \\
\hline $\begin{array}{l}\text { Transport } \\
\text { and } \\
\text { Warehousing }\end{array}$ & 6 & 13 & 10 & 9 & 6 & 9 & 229 & 205 & 8 & 27 & 16 & 16 \\
\hline Construction & 14 & 3 & 3 & 14 & 7 & 7 & 299 & 164 & 25 & 19 & 22 & 23 \\
\hline $\begin{array}{l}\text { Agriculture/ } \\
\text { Forestry }\end{array}$ & 4 & 3 & 5 & 5 & 9 & 5 & 174 & 144 & 11 & 16 & 12 & 11 \\
\hline $\begin{array}{l}\text { Accidents in } \\
\text { total }\end{array}$ & 44 & 48 & 38 & 53 & 53 & 39 & $\begin{array}{c}194 \\
8 \\
\mathbf{1 4 8}\end{array}$ & $\begin{array}{c}175 \\
5 \\
162\end{array}$ & 137 & 167 & 155 & 146 \\
\hline
\end{tabular}

As seen from the above, Table 1 figures are still extremely high rated, yet the trends cannot be flagged as favourable since various deviations do continuously arise. The number of fatalities and severe damages to health has not yet approached the zero level, since the Self-Employers, making up approx. $10 \%$ of the overall Construction Industry portion, yet contributing to the most hazardous group of people even charged by the entire occupational and educational cost package (trainings, courses, Personal Protective Equipment, Electrical Equipment Revisions, etc.) are excluded from the statistics. And this particular area is the one of minimized costs.

In order to be able to succeed in the Occupational Health and Safety Management, it is of a need to take into consideration the foregoing group of workers and to pay increased attention thereto starting at the initial commencement of works and continuing further on.

Causes of fatalities and severe damages to health remain unchanged - fall from height or into depth, loading/unloading accidents, electrical injuries, backfilling or accidents caused by other persons are all of concern [2].

Slips and trips are considered as other frequently identified causes of registered accidents. Despite the fact that consequences of these accidents are not always severe, from the statistical point of view, they form $2 / 3$ of all registered accidents. This issue has to be treated as early as in the stage of prevention. In the completion process of Units 3 and 4, six of ten accidents relate to slips and trips, while this type of the accidents happens due to the lack of attention, i.e. the reason No. 12 in compliance with the SR Regulation No. 500/2006 Coll., and not because of a defective or dangerous condition of roads or pathways.

\section{THE PRINCIPLES OF HUMAN RELIABILITY}

The principles of human reliability as a solid foundation for supporting those forms of behaviour that result in continuous improvement in human reliability. The five principles of human reliability used in nuclear industry are described below [3].

1. People are fallible and even the best of us make many mistakes. People have not only extensive abilities, but also their own limitations. One such drawback is the tendency to make mistakes. Human performance tools should not be the only line of defence in performing safety-critical activities. Other, more reliable forms of defence, such as technical 
elements, should be adopted as the measures ensuring the successful completion of planned activities.

2. Risk situations can be foreseen, managed or even avoided. Specific types of errors within certain assignments can be predicted. Recognizing the trap and communicating it to other workers allow us to control situations and prevent errors and many of unwanted events. By changing the attributes of a particular situation, in order to prevent or eliminate conditions that promote the error, the chance of error can be minimised or even eliminated.

3. Organizational processes and values also affect the behaviour of individuals. Organizations are driven by the achievement of goals, as they are of course required, and generation of electricity is the ultimate goal of all commercially oriented nuclear power plants. Accordingly, managers develop the procedures and values designed to manage individuals' behaviour. Essentially, the organization is a summary of the job performance divided into individual tasks coordinated to produce electricity in a safe and reliable manner. Work duties are fulfilled in terms of the company management planning as well as in compliance with the control systems that contribute to the majority of human reliability issues.

4. Employees achieve a high level of performance based on the support from senior staff, colleagues and subordinates. Safety and reliability are directly dependent on people's behaviour. Behaviour, positive or negative, is reinforced by immediate consequences or previous experiences. Behaviour is usually amplified by consequences. The most capable defence mechanisms to prevent unwanted events are in communication and positive feedback to the desired type of behaviour.

5. Undesirable events can be avoided by understanding the reasons behind the failure and realizing the consequences of previous events. Lessons learned from one's own as well as from other mistakes are important for the next steps. Sometimes, people make mistakes despite their best efforts and their reasons are a valuable view of how to predict, how to avoid them and how to deal them. By anticipating the way it can be avoided is the best and cost-effective tool to prevent it.

\section{How to prevent errors - error precursors}

The likelihood that an individual or a team performing a job is mistaken is affected by the presence of performance factors (such as time, stress and / or fatigue etc.). These are known as error precursors that interfere with successful performance and increase the likelihood of error. Many conditions are worth creating errors.

The "TWIN" model describes in detail the conditions (error precursors) associated with the occurrence of events that preceded errors. The common error precursors can be categorized in terms of the attributes defined below:

$\mathrm{T}$ - Requirements required to accomplish the task - mental, physical and team requirements that can stimulate an individual or their limit values within the assigned task.

W - Working environment - affects the conditions of the workplace itself, which can affect the level of individual performance.

I - Individual Abilities - The unique mental, physical and emotional characteristics of a particular person having an impact on task failure.

$\mathrm{N}$ - Human nature - characteristics, dispositions and limitations common to all human beings that can cause an individual to incline to the wrong side in case of unfavourable conditions.

The error precursors themselves do not determine the situation in which the error occurs. A human act or task performance must either be planned or must occur in the presence of error precursors to be considered as an error. If it is already known, its removal or alleviation will ensure the adoption of defence mechanisms that eventually reduce the risk of error [3]. 


\section{Human Behaviour}

Every one of us makes mistakes and will do so, regardless of trainings and motivation. Just as a matter of interest that an adult person makes 35,000 deliberate decisions a day and min., $1 \%$ of these decisions, approx. 350, are decisions considered as critical or dangerous [4].

As for instance, ascending and descending stairs without holding a handrail, texting while walking or even while driving a car, walking on wet staircase or pavement might be very dangerous as well, sporting without use of necessary protectors, etc. Frankly said, how many of you have already made similar risky decisions?

In workplace, however, consequences of such failure, failure resulting from an incorrect decision or dangerous behaviour, may impact a human being considerably. Analyses of accidents and incidents show that 8 out of 10 accidents are caused by a human failure. Many serious accidents, e.g. Texas City Explosion, Chernobyl, Costa Concordia, Deepwater Horizon, were initiated by a human failure. To prevent accidents and damages to health of workers, companies must manage human failures to prevent, mainly adoption of technical and engineering measures, such as tools and procedures enhancing the human behaviour and decision-making process in overall, mainly by involving psychologists and field professionals.

Behaviour is an aspect of a human activity perceived by an observer from "the outside" and impartially. However, psychology is not limited only to description of external behaviour and analysis, yet it tries to analyse the "background process", i.e. our psychological processes and mental properties. Reactions, responses, actions, external expressions evoked by living, including the way of speaking, are considered as a behaviour.

Actions of a human are to be considered as all made deliberately. They represent the most complicated expressions of behaviour. In addition to the mental state and the highest mental functions (thinking, speaking, decision-making), personal qualities contribute, too. A human deliberately acts on the environment and himself by his or her acting. Human being is an active creature. He or she needs acting for the existence to persist. Basic forms of human activities are game, learning and work. Mental processes, states and personal qualities are formed through human's activities. If a human devotes himself or herself to music, he or she improves his or her musical perception. A man can also refrain from an unsuitable unwanted activity or its expressions (e.g. give up certain hobbies in the interest of others, more important ones). When controlling negative passions, any behavioural negative expressions, the human acquires positive characteristic and expected properties. He or she cultivates a strong will by coping up with barriers. Activity (or its limitation) is a fundamental condition of formation and mental life development. The more assorted activity the human performs, the more intensively and universally his or her mental life develops. Human's mental life is reflected in his or her activity. For example, existence or the level of the sport abilities might be detected only in sport, i.e. organisational competences only in the management process. Human activity is also a criterion of correctness of the objective reality reflection in human's psyche. It results from the aforementioned relations of psyche and activities, whereas the human's psyche and activities, they both form a single unit. We must influence the human's psyche if we want to achieve a safe occupational performance (the one of no unwanted events and actions) [5].

There are three basic safe behaviour improvement tools. Education \& training, communication and inspection.

\section{Inspection and observations}

Culture is all about behaviour, and, before we start trying to influence behaviour, we really should begin with understanding what the current behavioural patterns are like. This is where observation comes in. [6] Inspection is the key safety tool and recently has been considered as the most important one. Many articles dealing with the issue of inspections do exist. The definition of inspection according to the "National Safety Council" is as follows: 
"Main objective of inspection is to reveal potential threat, so it can be eliminated before it causes an accident. Through inspection, we can define what has to be corrected or improved to be able to work in line with acceptable standard from the viewpoint of safety as well as construction or operation."

In order the inspection to be precise, a number of Safety Supervisors in MO34 Construction site had increased, yet enforcement of their presence during the night shifts, weekends and national holidays was put in place. The number of Specialists scaled up to 35, while additional 15 were assigned to the Irregular Safety Regime, focusing thereby mainly on the classified technical equipment, scaffoldings, works at height, binding and lifting operations, etc.

It is important all Supervisors do inspections, advising, on-the-spot-actions and feedback right in the workplaces of contractors. Effort is made to save the Supervisors from excessive administration, which in practice equals to approx. 6 hours/day. Legitimacy of their activity is assured by the fact that from 2014 to 2016 they had recorded 79,695 inspections and removed as much as 752 deficiencies of immediate danger to health and ensured correction to more than 40,000 small deficiencies. This approach and inspections minimise the time of exposure to threat or elimination of the threat itself.

If matching preventive tools mentioned in the lower lines (see Fig. 1 of the classic Heinrich Safety Pyramid) shall be in place, we might be able to minimise the occurrence of the upper line events.

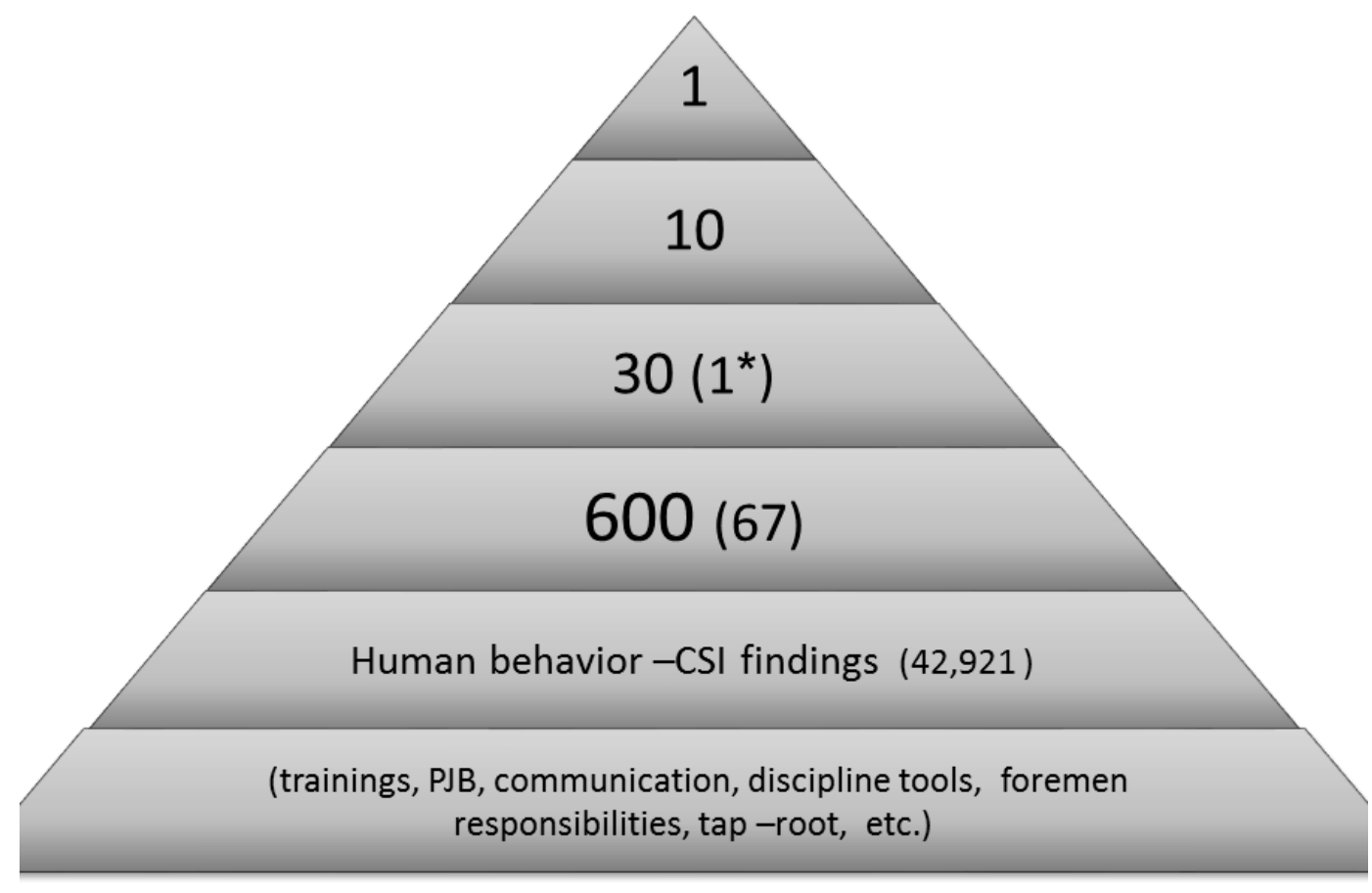

Fig. $1 \mathrm{H} . \mathrm{W}$. Heinrich classic safety pyramid + preventive tools

To ensure the effectiveness of inspections, some other criteria must be fulfilled. It is important all inspections are:

- performed regularly,

- at expected level,

- purposeful and corrective measure-approached,

- duly documented,

- feedback-directed.

A special application in the MO34 project conditions has been developed and is at the time operated by BOZPO, s.r.o. Company upon requirements of the project team. CSI Application 
(Construction Safety Indicators) is the one of focus. The main benefit of this software is the quantity of data it may offer, mainly:

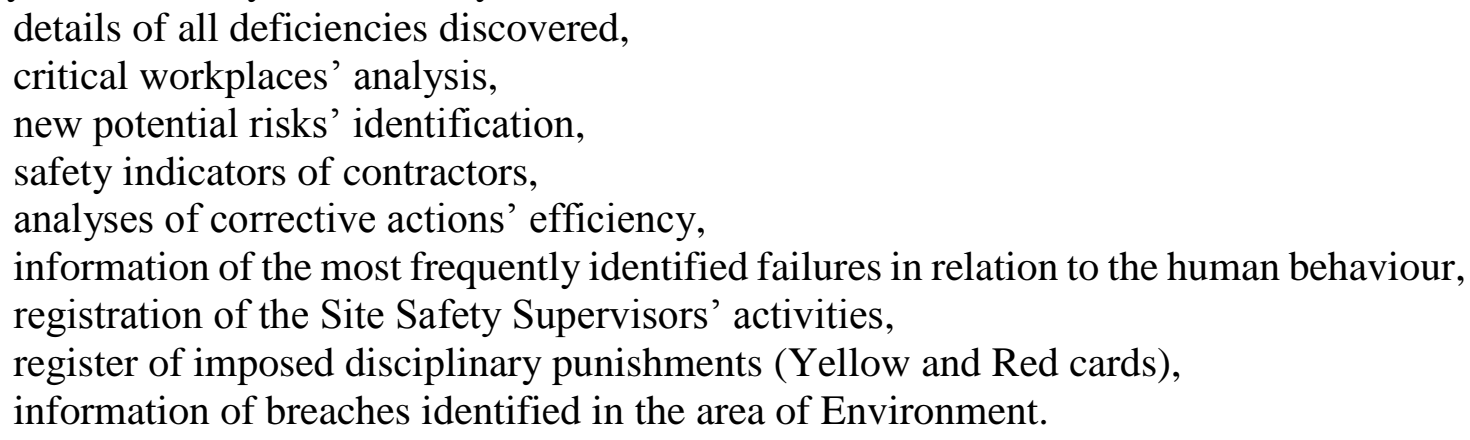

Thanks to this information we are able include corrective and preventive measures to the monthly inspections carried out in cooperation with contractors and evaluate their efficiency as further.

From the human behaviour and improvement viewpoint, inspections should be supported by three psychological discipline and motivation tools and correctly feedback-applied.

The psychological motivation and disciplinary feedback-impulses are as follows.

\section{Positive impulse}

Expected behaviour repeats if rewarded by a bonus, acknowledgement or appreciation. For this purpose, financial vouchers of $€ 5$ - 20 are distributed in the premises of NPP Mochovce, Units 3 and 4 to workers who may use these vouchers in all the site catering facilities. Some little promotional items are being distributed, as well. It is important to award a worker who observes Safety rules and reacts to the questions related to the Occupational Health and Safety. For the period of positive incentive and remuneration, approx. 700 financial vouchers and approx. 1,500 non-financial promotional items have been assigned to the site persons for positive behaviour.

\section{Negative impulse}

Expected behaviour is identified as repetitive with a purpose to supress the negative consequences such as noise, signal, warning, etc. In this case, the warning serves as a negative feedback. It is always very important to at least warn or notify the workers of the rules they are breaching, furthermore an explanation of eventual consequences their acting might have, is recommended to be brought in. In order to prevent any unpleasant ("negative") behaviour to occur, compared as for instance to an unfastened safety belt, observance of safety rules and safe behaviour is hereby recommended.

\section{Punishment}

Expected behaviour is found to happen more often in order to prevent negative consequences to repeat, i.e. punishment and sanctions. This tool is the least popular one to be followed by the workers. Under the construction conditions, comparing to soccer, a system of Yellow and Red cards has been applied. In practice it means that if a worker breaches rules, he or she is penalised by a Yellow card valid for a period of the following three months. If at the same time he or she is penalised with another Yellow card, he or she must attend a training in OH\&S, FP and ENV and only after successful passing of the test he or she may continue at work. This form of education is successful on $90 \%$. If the worker breaches rules for the third time, he or she might be applied a Red card. His or her site access is suspended for a defined period of time.

The main goal of all three impulses is to teach the workers to no existence of shortcuts in the area of Occupational Health and Safety. None of the shortcuts pays off, whereas even the profit earned from such shortcuts is much smaller than the potential loss. 
Of course, the major loss from the OH\&S violations and shortcuts we may face is damage to our health. We remind workers of this fact on a regular basis, during inspections, trainings, and various communication campaigns.

\section{Effective safety communication}

Important and inseparable part of the Safety Management System is the method the OH\&S communication is forwarded throughout the organisation to employees, i.e. communication maintained with all contractors and team members. Thus, it is necessary to set up a large proportion of communication means.

The definition of communication is simple "Communication can be: exchange of information, ideas, opinions and feelings among living beings usually in a form of a common system of symbols." The method of adjusting the information exchange in MO34 completion process shall be seen below. Following are the forms the communication may be structured to:

- Builder $\Leftrightarrow>$ Contractor

- Builder $\Leftrightarrow$ Construction workers

- Civil contractor $<=>$ Subcontractors

- Workers among each other

- Campaign must be directed (target group)

- Simple and understandable

- Actual (reflecting current issues)

- Supported by discussions and accompanying events

Of course, many communication methods and ways influence people to stop for a while and think; campaign may be negative, positive or even shocking. Mainly in the spirit of "the end justifies the means". Many different approaches to this issue existed also in the completion process of Unit $3 \& 4$. As an example of good practice and perhaps for inspiration, you may take a look at some communication campaigns, their main ideas and messages.

\section{What if - Campaign - 2013}

This campaign was difficult for emotions to be dealt with, since the content of this campaign needed to be emphasised in a suitable manner. For this purpose, two lapses of the campaign were selected: Phase 1, the so-called teasing, i.e. placing a question with many potential answers to come up as next; the aim was to force the workers to think of the "What if?" into details.

These posters were afterwards installed in the site premises and after a certain time these questions were supplemented by answers. Of course, the campaign was communicated in many practical trainings as well as directly in workplaces where individual topics of the campaign were discussed.

\section{Together we will save all dangerous situations - Campaign - 2016}

Face of the campaign, a well-known Slovak hockey goalkeeper, Ján Laco, was also awarded as the best goalkeeper of the tournament, what has not been achieved by any other Slovak goalkeeper, yet. Video is available at https://www.seas.sk video. [7], where Ján Laco reminds and tries to encourage workers not to be indifferent. Many times, it is enough to call a free of charge phone No. available 24/7 and report any identified shortcoming or event. Ján Laco emphasized the importance of the use of PPE. Can you imagine a goalkeeper without a helmet or equipment at today's hard shots? Can you imagine a team sport without any cooperation?

\section{Take Care of Yourself, We Wait for You at Home - Campaign - 2017}

Workers following $\mathrm{OH} \& \mathrm{~S}$ rules who are able to react to the safety-related questions without doubts are always remunerated; we were trying to identify the background of their 
motivation, i.e. what forces them to work safely. Almost half of the respondents pointed to their responsibility towards their families. They cannot afford an accident neither they may threaten their friends and families by hazardous acting. And just this very frequent answer motivated us to organise a "Family Day" for employees. Children were given an opportunity to discuss and solve assigned $\mathrm{OH} \& \mathrm{~S}$ tasks in a competitive and entertaining manner, making a video for us thereby named "Take Care of Yourself, We Wait for You at Home" published at https://www.seas.sk/video.

\section{DISCUSSION ON RESULTS}

Health and life of our friends and colleagues is considered as the greatest asset for all those employed in the field of Safety, yet their protection is our priority. The Slovak legislation, lined to the European directives and regulations, is considered as strict and purposeful not only in the field of Construction, but also in other relevant disciplines as maintenance, assembly and disassembly operations, etc. Current form has been paid by health and lives of workers from all the disciplines. It is very important to have a well-established Safety Management System further supported by good practice, follow-up reviews and effective control mechanisms so that industrial accidents are thereby to be prevented.

To observe the legislative-based requirements in today's world is just not enough and thus we have to start sharing the practical approach and so as the Safety Management Tools. If wellbased and verified experience is perceived as a secret or a know-how, our workers will still pay for their mistakes by the most valuable asset they have. However, if practical experience is to be shared widely, we may be able to help in protecting the lives and health of our workers.

\section{CONCLUSION}

Construction of a nuclear power plant is a project of a worldwide focus, since the approach to the Construction-Phase Safety is an important indicator of the Investor's approach and the key one from the nuclear installation operation viewpoint. One of the ways to evaluate successfulness or failure of the Safety Management System is to compare the obtained results with the ones presented in the Slovak Republic Construction industry statistics. The Frequency Rate (number of accidents per million hours worked) obtained under the completion process conditions is 3.5 times better than in Slovakia as in overall, and the Severity Index (number of hours lost due to sick leave / unit of time) under the completion process conditions is 8.5 times better than indicators of the Slovak Statistical Office in terms of the Construction industry.

\section{References}

[1] www.nip.sk National Labour Inspectorate Kosice. Vývoj úrazovosti s t'ažkou ujmou na zdraví od roku 1997. (The development of incidents with an impact on health since the year 1997.) [Online]. [Accessed: 04-2019] Available at https://www.ip.gov.sk/?s=statistiky+urazovosti

[2] HILL, D. C. 2004. Construction Safety Management and Engineering. Illinois, American Society of safety Engineers, p. 3. ISBN 1-885581-46-7

[3] www.standrads.doe.gov Department of Energy United States of America Human performance Improvement Handbook Volume 1: Concepts and principles pp. 19 -20, 32. [Online]. [Accessed: 04-2019] Available at https://www.standards.doe.gov/standards-documents/1000/1028-BHdbk2009.../file

[4] HOOMANS, J. 2015. 35,000 Decisions: The Great Choices of Strategic Leaders Leading Edge Journal [Accessed: 03-2019] Available at https://go.roberts.edu/leadingedge/the-great-choices-ofstrategic-leaders 
[5] www.muni.cz ŘEHULKA, E. Úvod do studia psychologie. (Introduction to Psychology.) pp. 7 12 [Accessed: 03-2019] Available at https://is.muni.cz/el/1441/podzim2009/SZ7BP.../ UVODDOPS.pdf

[6] SHARMAN, A. 2014. From Accident to Zero. Maverick Eagle Press, p. 81. ISBN 978-0-9929906$0-2$

[7] www.seas.sk LACO, J. Spolu vychytáme nebezpečné situácie! (Together we will eliminate dangerous situations). [Online]. [Accessed: 05-2019] Available at https://www.seas.sk/clanok/janlaco-spolu-vychytame-nebezpecne-situacie/252

\section{ORCID}

Karol Balog

0000-0002-0804-8338 